\title{
Development of a mass spectrometry imaging method
}

\section{for detecting and mapping graphene oxide nanoparticles}

\section{in rodent tissues}

Hélène Cazier ${ }^{\alpha}$, Carole Malgorn ${ }^{\alpha}$, Nathalie Fresneau ${ }^{\alpha}$, Dominique Georgin ${ }^{\alpha}$, Antoine Sallustrau ${ }^{\alpha}$, Céline Chollet $^{\alpha}$, Jean-Claude Tabet ${ }^{\alpha}$, Stéphane Campidelli ${ }^{\beta}$, Mathieu Pinault ${ }^{\alpha}$, Martine Mayne ${ }^{\alpha}$, Frédéric Taran ${ }^{\alpha}$, Vincent Dive ${ }^{\alpha}$, Christophe Junot ${ }^{\alpha}$, François Fenaille ${ }^{\alpha}$, Benoit Colsch $^{\alpha^{*}}$

${ }^{\alpha}$ Université Paris-Saclay, CEA, INRAE, Médicaments et Technologies pour la Santé (MTS), 91191 Gif-sur-Yvette, France. ${ }^{\beta}$ Université Paris-Saclay, CEA, CNRS, NIMBE, 91191 Gif-sur-Yvette, France.

*Corresponding author: benoit.colsch@cea.fr

Table S1 : List of the molecular ions detected by LDI-MSI.

Figure S1: LDI mass spectra of a mixture of SDBS/GO solution, SDBS solution only and GO solution without SDBS.

Figure S2: MALDI mass spectra of $\mathrm{rGO}$ obtained using several MALDI several commonly used MALDI matrices such as TCNQ, 9-AA, THAP, DHAP, DAN, HCCA, DHB and SA at $0.1 \mathrm{mg} / \mathrm{mL}$.

Figure S3: Comparison of GO and rGO signatures acquired or not on tissue section.

Figure S4: Impact of laser parameter optimizations effect on GO signal onto tissue section.

Figure S5: LDI mass spectra obtained from the GO calibration curve on lung tissue. 
Table S1 : List of the molecular identities of the observed ion by LDI-MSI.

\begin{tabular}{|c|c|c|}
\hline $\mathrm{m} / \mathrm{z}$ & Attributions & Molecules \\
\hline 24.00 & Graphene oxide moiety & $\mathrm{C}_{2}^{-}$ \\
\hline 26.00 & Graphene oxide moiety & $\mathrm{C}_{2} \mathrm{H}_{2}^{-} \cdot$ \\
\hline 36.00 & Graphene oxide moiety & $\mathrm{C}_{3}^{-}$ \\
\hline 42.00 & Graphene oxide moiety & $\mathrm{C}_{2} \mathrm{H}_{2} \mathrm{O}^{-}$ \\
\hline 48.00 & Graphene oxide moiety & $\mathrm{C}_{4}^{--}$ \\
\hline 60.00 & Graphene oxide moiety & $C_{5}$ \\
\hline 72.00 & Graphene oxide moiety & $\mathrm{C}_{6}^{-}$ \\
\hline 84.00 & Graphene oxide moiety & $\mathrm{C}_{7}=$ \\
\hline 96.00 & Graphene oxide moiety & $\mathrm{C}_{8}^{-}$ \\
\hline 108.00 & Graphene oxide moiety & $\mathrm{C}_{9}^{-}$ \\
\hline 119.06 & ND & \\
\hline 183.00 & ND & \\
\hline 197.01 & ND & \\
\hline 199.03 & ND & \\
\hline 211.01 & ND & \\
\hline 225.03 & ND & \\
\hline 239.04 & ND & \\
\hline 253.05 & ND & \\
\hline 267.07 & ND & \\
\hline 297.14 & SDBS chain C11 & $\mathrm{C}_{16} \mathrm{H}_{25} \mathrm{O}_{3} \mathrm{~S}^{-}$ \\
\hline 311.17 & SDBS chain C12 & $\mathrm{C}_{17} \mathrm{H}_{27} \mathrm{O}_{3} \mathrm{~S}^{-}$ \\
\hline 325.20 & SDBS chain C13 & $\mathrm{C}_{18} \mathrm{H}_{29} \mathrm{O}_{3} \mathrm{~S}^{-}$ \\
\hline 339.34 & SDBS chain C14 & $\mathrm{C}_{19} \mathrm{H}_{31} \mathrm{O}_{3} \mathrm{~S}^{-}$ \\
\hline 355.27 & SDBS chain C15 & $\mathrm{C}_{20} \mathrm{H}_{33} \mathrm{O}_{3} \mathrm{~S}^{-}$ \\
\hline
\end{tabular}




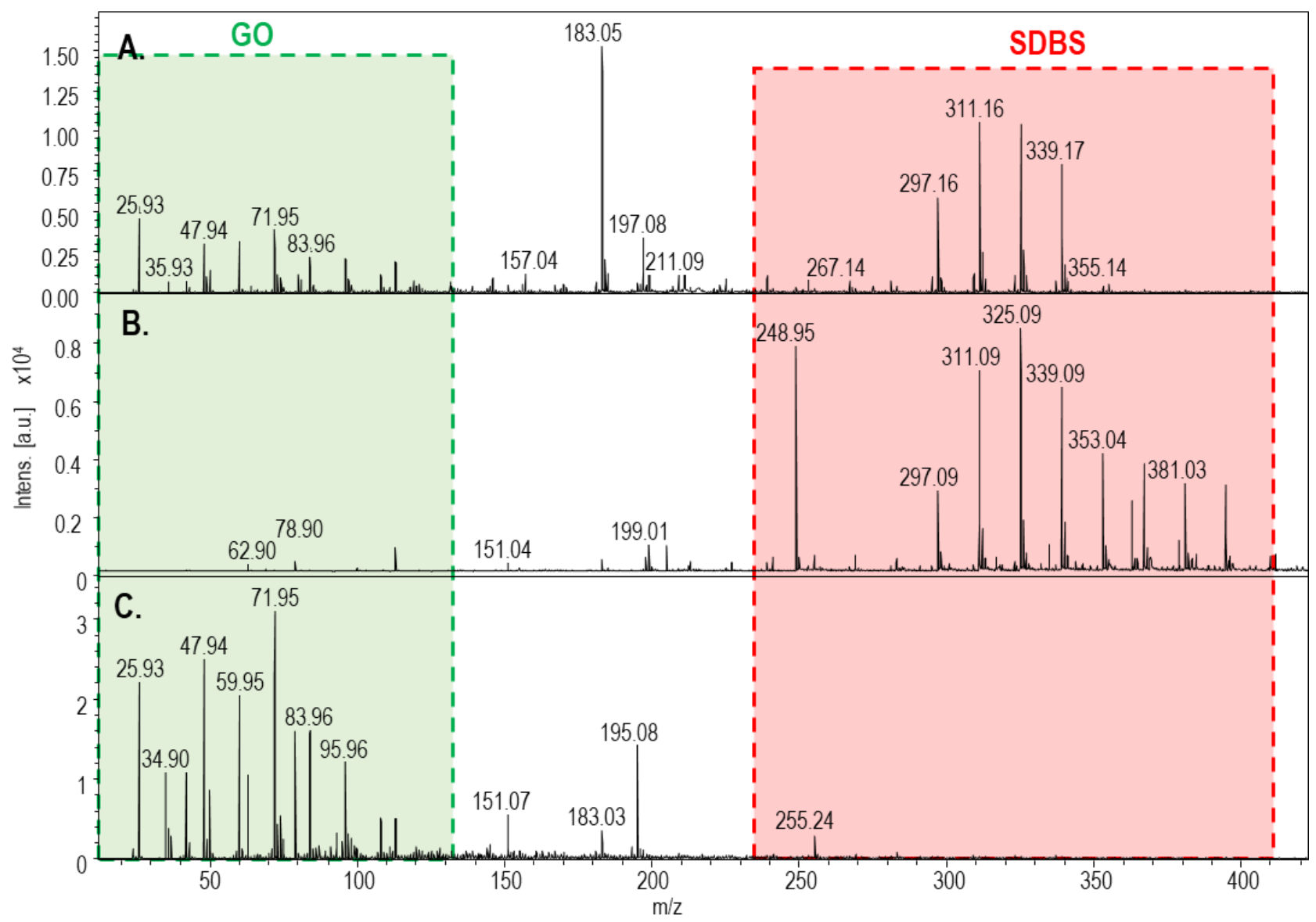

Figure S1: LDI mass spectra of a mixture of SDBS/GO solution (A), SDBS solution only (B) and GO solution without SDBS (C). Spectra comparison allows us to specifically assign the SDBS signature between $\mathrm{m} / \mathrm{z} 290$ and $\mathrm{m} / \mathrm{z} 400$ and the GO signature between $\mathrm{m} / \mathrm{z} 20$ to $\mathrm{m} / \mathrm{z}$ 120. LDI-MS analyses of GO and SDBS alone and mixed on MTP ground steel plate with reflectron acquisition mode and negative ionization mode. The DIE was $80 \mathrm{~ns}$ with an accumulation of 4000 shots per spectrum at $2 \mathrm{kHz}$ and a laser intensity of $90 \%$. 

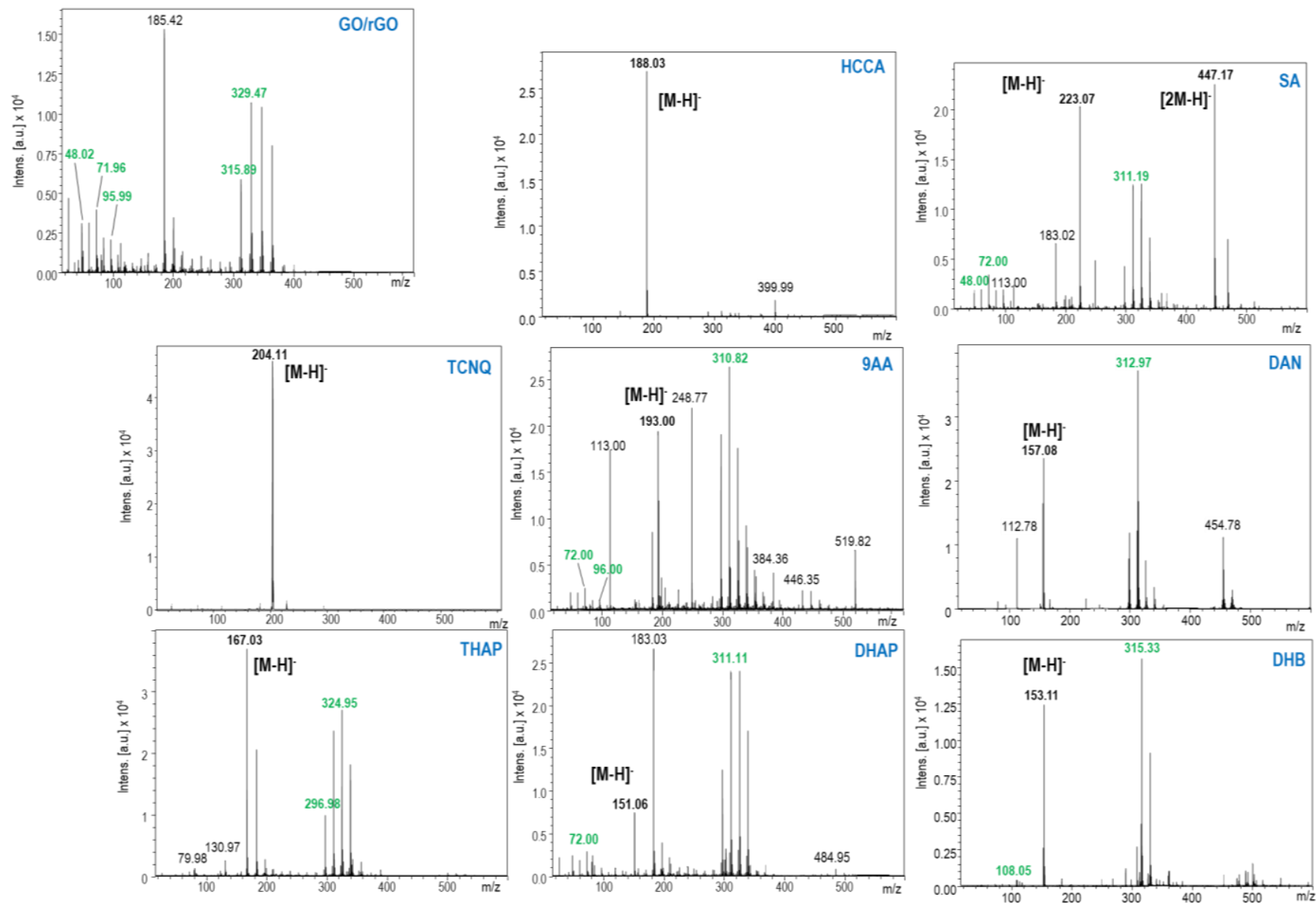

Figure S2: MALDI mass spectra of rGO obtained using several MALDI several commonly used MALDI. Graphene oxide at $100 \mathrm{ng} / \mu \mathrm{L}$ was analyzed with MALDI matrix as TCNQ, 9AA, THAP, DHAP, DAN, HCCA, DHB and SA matrices at $10 \mathrm{mg} / \mathrm{mL}$ (ACN/H2O (0.1\% TFA), 50:50, v/v). Spectra were acquired in reflectron and negative ionization mode with a DIE of $80 \mathrm{~ns}, 4000$ laser shots per spectrum at $2 \mathrm{kHz}$ and a laser intensity of $90 \%$. 

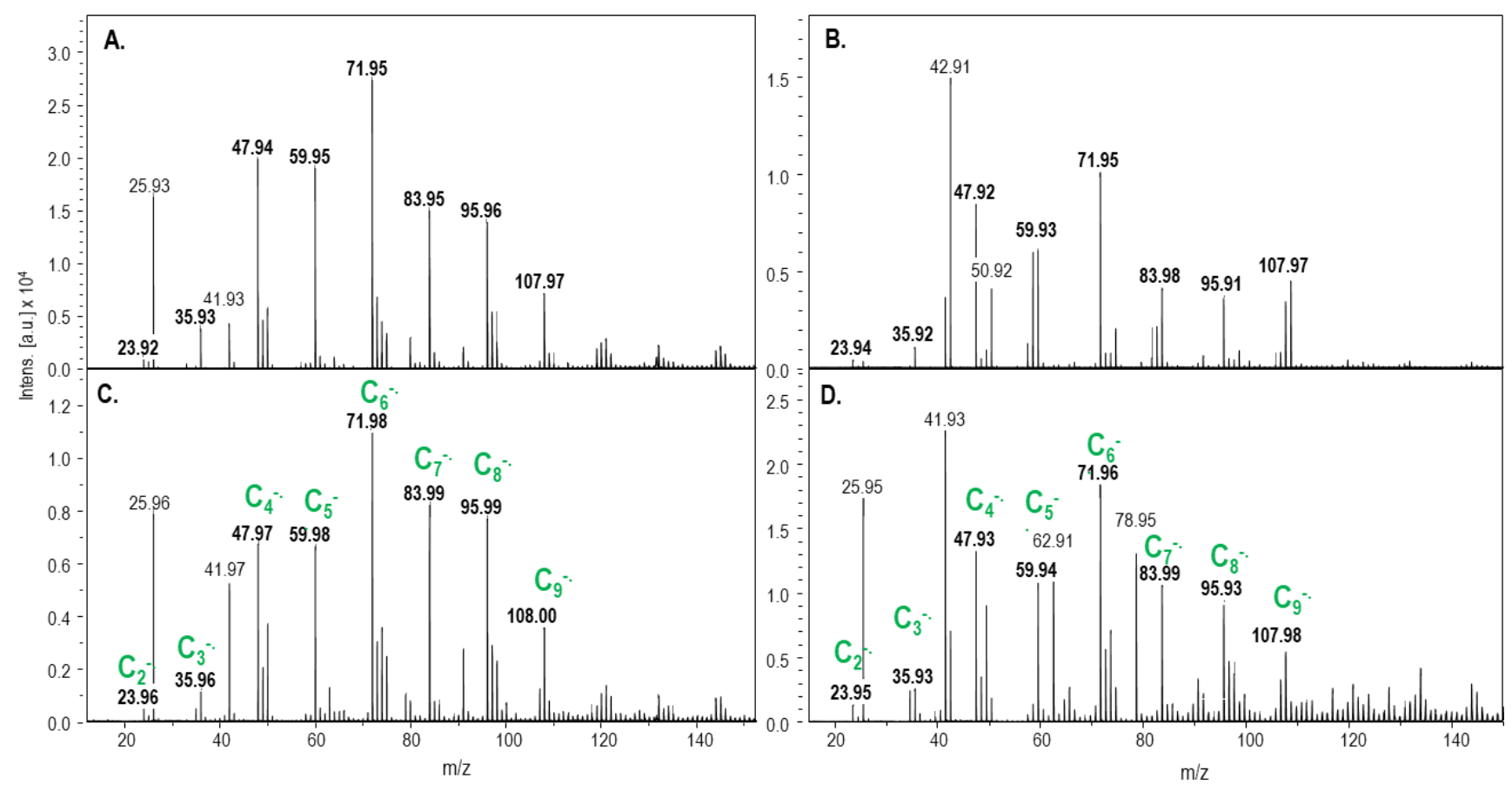

Figure S3: Comparison of GO and rGO signatures acquired or not on tissue section by LDI-MS. The spectra in $A$. and $B$. represent the $\mathrm{rGO}$ and $\mathrm{GO}$ on the ITO slide. The C. and D. spectra represent the $\mathrm{rGO}$ and $\mathrm{GO}$ on a $12 \mu \mathrm{m}$ liver section. The results are obtained after an accumulation of 1000 laser shots per spectrum at $2 \mathrm{kHz}$, a DIE of $10 \mathrm{~ns}$ and a laser fluence of $90 \%$. 

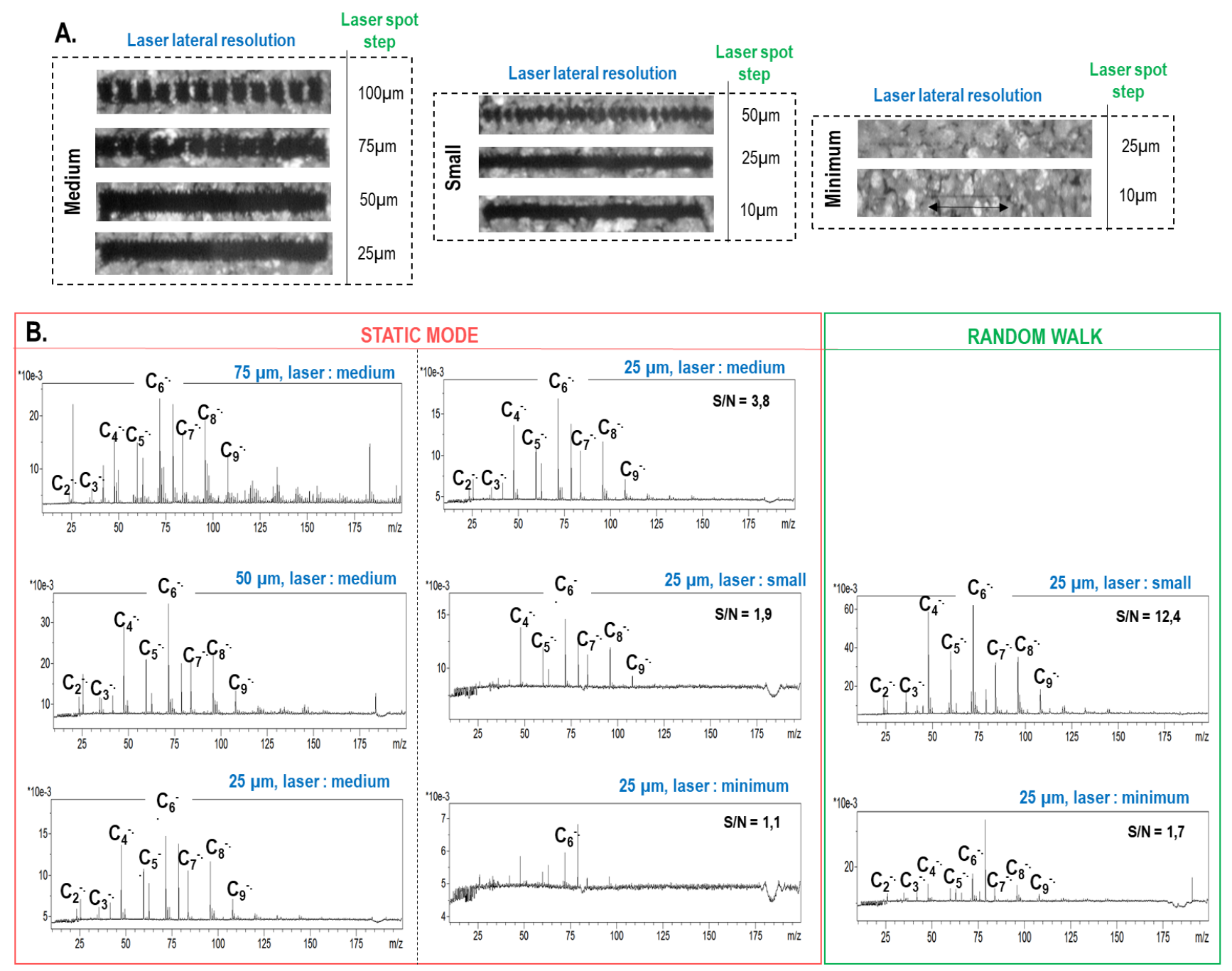

Figure S4: Impact of laser parameter optimizations and on GO signal onto tissue section. A. Evaluation of the laser impacts size with "medium", "small" and "minimum" focalizations in the HCCA matrix deposited using an airbrush system. B. rGO spectra acquired on $12 \mu \mathrm{m}$ lung sections with "medium", "small" and "minimum" laser focalizations at a spatial resolution of 25, 50 or 75 $\mu \mathrm{m}$ with and without laser movements. The noise signals correspond to those of the $\mathrm{m} / \mathrm{z} 72$ ion and are calculated manually on the FlexImaging 4.1 software from the average spectra obtained over the acquired lung area. The ROIs are of similar sizes. 


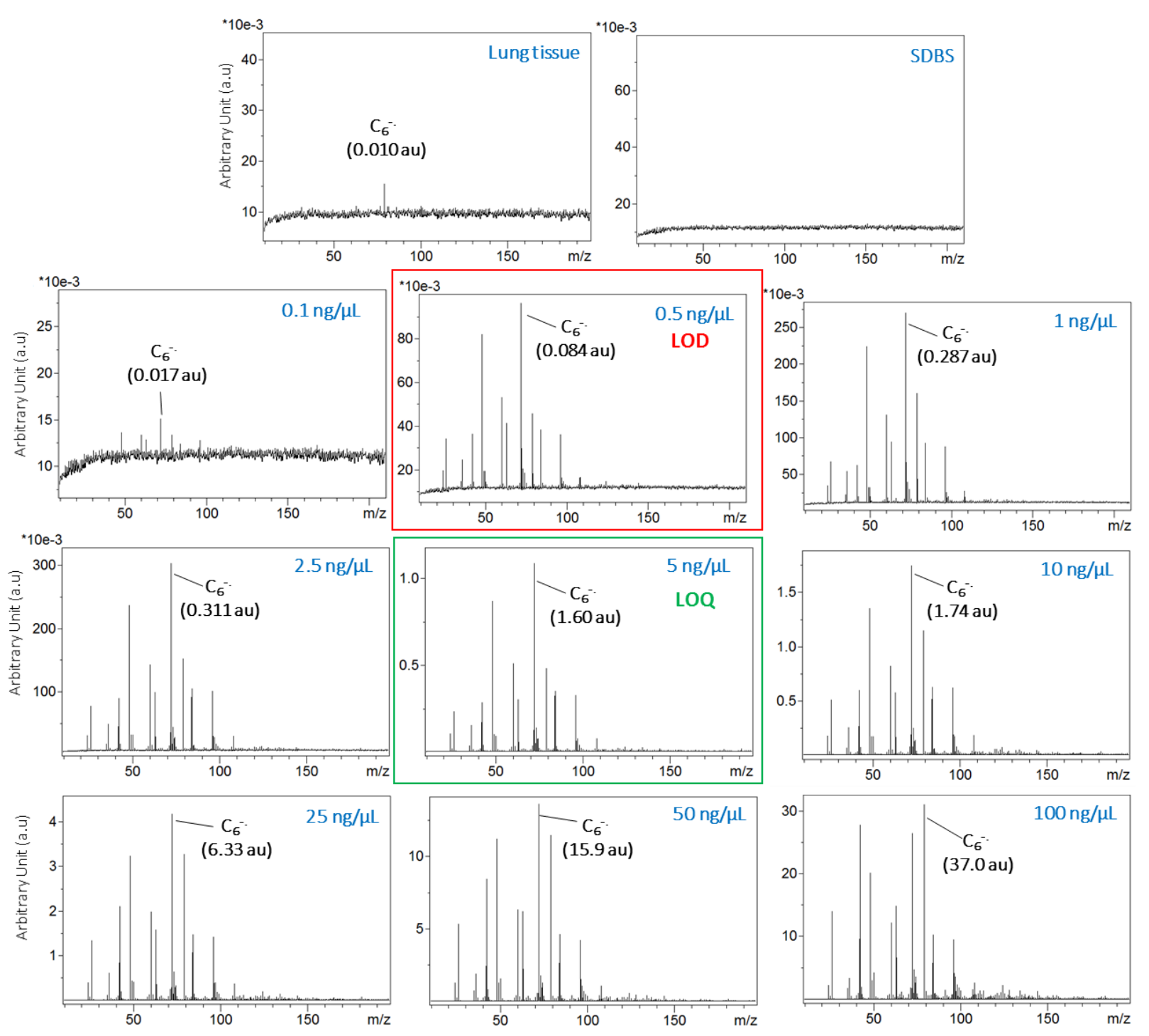

Figure S5: LDI mass spectra obtained from the GO calibration curve on lung tissue section. GO spectra were acquired on lung tissue $(12 \mu \mathrm{m})$ after an accumulation of 1000 laser shots per spectrum at $2 \mathrm{kHz}$, a DIE of $10 \mathrm{~ns}$ and a laser fluence of $90 \%$. Intensities (a.u.) were average onto 3 GO spots for each concentration. LOD was estimated as a signal to noise above 3. LOQ was estimated based on accuracy measurements. 